\title{
Evaluating the discriminatory power of a dissolution assay for rosuvastatin calcium capsules: Solid-state properties and dissolution media
}

\author{
Marilene Lopes Ângelo ${ }^{*}$, André Luís Morais Ruela², Anna Clara Marques Ferreira ${ }^{1}$, \\ Marcus Vinicus de Faria Ramos ${ }^{1}$, Cristina Martiniano Montanari ${ }^{3}$, Lucélia Magalhães da Silva ${ }^{4}$, \\ Magali Benjamim de Araújo ${ }^{1}$
}

${ }^{1}$ Department of Pharmacy, Faculty of Pharmaceutical Sciences, Federal University of Alfenas, Alfenas, MG, Brazil, ${ }^{2}$ School of Pharmacy, Federal University of Ouro Preto, Ouro Preto, MG, Brazil, ${ }^{3}$ Department of Clinical Analysis, Toxicology and Food Science, Faculty of Pharmaceutical Sciences, University of São Paulo, Ribeirão Preto, SP, Brazil, ${ }^{4}$ Federal Institute of Paraná,Palmas, PR, Brazil

\begin{abstract}
We propose to evaluate the dissolution properties of rosuvastatin calcium (ROSC) capsules in different media to characterize the discriminatory power of the assay method. Dissolution assays were performed in media with different $\mathrm{pH}$, and including the surfactant sodium dodecyl sulfate (SDS). Several immediaterelease formulations were manufactured using the commercial raw material characterized as amorphous solid. The hydrophobic adjutant magnesium stearate was employed in some formulations due to its negative effect in the wettability and dissolution efficacy of solid dosages. These formulations showed the lower dissolution efficacy values in media without surfactant; however, when SDS was added to the medium, the dissolution efficacy increased, and the discriminatory power was lost. In spite of micellar solubilization does not increase the ROSC solubility, it modifies the discriminatory power of the assay method, increasing the wettability of the powder mixtures. The crystalline form M of ROSC was recrystallized in our laboratory, and it showed lower solubility in water than amorphous solid. However, its dissolution properties were not influenced by SDS. These results are important to develop dissolution assays for other hydrophilic drugs with increased water solubility, once that dissolution media with surfactants increase the wettability of the formulations, leading to an overrated dissolution rate.
\end{abstract}

Keywords: Dissolution. Crystal polymorphism. Solid dosage form. X-ray powder diffractometry. Thermal analysis. Solubility.

\section{INTRODUCTION}

Rosuvastatin calcium (ROSC) (Figure 1) is a lipidlowering drug that competitively inhibits the enzyme hydroxymethylglutaryl-coenzyme A (HMG-CoA) reductase in the liver. HMG-CoA reductase catalyzes the conversion of HMG-CoA to mevalonic acid, representing the rate-limiting step in cholesterol biosynthesis (Alshora et al., 2016; Lee et al., 2014). ROSC is a hydrophilic statin, and Food and Drug Administration approved it

\footnotetext{
*Correspondence: M. L. Ângelo. Departamento de Alimentos e Medicamentos, Faculdade de Ciências Farmacêuticas, Universidade Federal de Alfenas. Rua Gabriel Monteiro da Silva, 700, Prédio D, Sala 307, 37130-001 - Alfenas - MG, Brazil. E-mail: marialfenas@yahoo.com.br
}

in 2003. It was the second most prescribed drug among global pharmaceutical products in 2014 , being primarily recommended to reduce plasma cholesterol levels and to prevent cardiovascular diseases (Lee et al., 2014; PatilGadhe, Pokharkar, 2016; Sterk et al., 2016; Zhou et al., 2013).

The absolute oral bioavailability of ROSC is low (about 20\%), which is mainly related to its hydrophilic character $(\log \mathrm{P}$ octanol/water $=0.13)$ (Moffat, Osselton, Widdop, 2011; Balakumar et al., 2013). The hydrophillic statin exists as an anion at physiological $\mathrm{pH}$, and it requires membrane transporters to be taken up into the cell, as the organic anion transporting polypeptides located on the brush-border membrane of the small intestinal enterocytes. ROSC is also excreted across the apical membrane of 


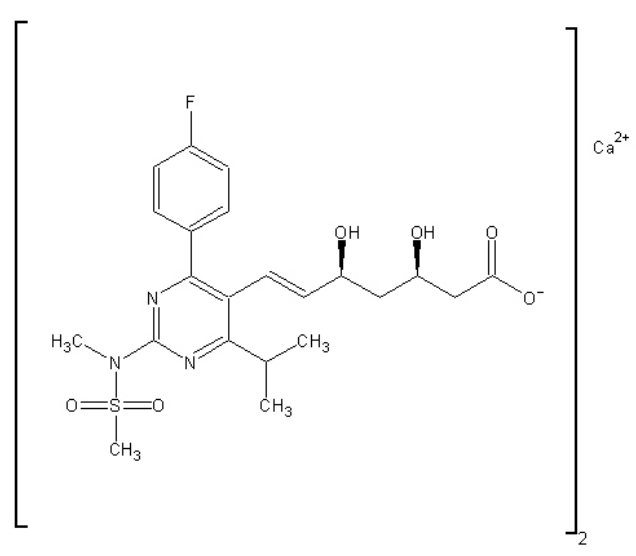

FIGURE 1 - Structure of ROSC.

the intestinal cells by efflux transporters, which also contributes to its limited bioavailability. Based on these considerations, some conventional formulations, such as hard gelatin capsules, are an easy and simple strategy to improve the drug release, increasing its availability for drug absorption sites in the GI tract after oral administration (Varma et al., 2011; Shen et al., 2015; Li et al., 2011). Others advantages of the capsules are the relative low cost of the materials and enhanced patient compliance. To assure the quality of these pharmaceutical dosage forms, dissolution assays have been performed in the quality control routine. However, the discrimatory power of these in vitro assays is an important parameter to be determined once the dissolution assay methods have been applied for delineating dosage forms, which searches for formulations with enhanced drug release profiles. When drugs with poor permeability and low bioavailability are evaluated, such as ROSC, its dissolution profile can be a tool for screening among several formulations, selecting those ones with improved dissolution properties (Peppas, Narasimhan, 2014; Qureshi, 2006). To achieve these goals, the dissolution testing should detect differences among several formulations, which can be only assured if the discriminatory power of the assay method was exhaustively studied (Matsui et al., 2016; Hoti et al., 2008).

In the light of these considerations, there are several factors affecting the dissolution properties from pharmaceutical dosages, which include the solid-state polymorphism (Snider, Addicks, Owens, 2004; Corrêa et al., 2016). The pharmaceutical industry manufactures solid dosage forms of ROSC using the amorphous solid, which has been reported as a solid-state form that shows satisfactory stability and low tendency to crystallize. On the other hand, several crystalline forms of ROSC have been described, including the crystalline forms A, B, B1, C, M, R, S, and TW1 (Sethi et al., 2010; Taylor, 1999;
Sahadeva et al., 2011; Booth et al., 2009; Blatter Van Der Schaaf, Szelagiewicz, 2006; Nishiguch, Inakoshi, 2013). The solid-state properties of the drug, mainly its solubility in water, may exert a significant effect on its in vitro dissolution properties from solid dosages, leading to different in vivo plasma profiles (Bonfilio et al., 2014).

In this study, we evaluated the discriminatory power of a dissolution assay for ROSC capsules. For this, the dissolution properties of seven formulations prepared with commercial raw material (amorphous power) were evaluated under different experimental conditions, including media with different $\mathrm{pH}$ and using the anionic surfactant sodium dodecyl sulfate (SDS). One formulation with enhanced dissolution properties was selected to be manufactured using the crystalline form M of ROSC, recrystallized and characterized in our laboratory. After performing these studies, the discriminatory power of the dissolution assay was evaluated under different experimental conditions, which demonstrated the importance of the appropriate selection of the experimental conditions.

\section{EXPERIMENTAL}

\section{Chemicals, standards and reagents}

All reagents were of analytical grade. The raw material of ROSC (assigned purity 101.43\%) was acquired from a pharmaceutical distributor (São Paulo, São Paulo, Brazil), and ROSC standard (99.8\%) was purchased from Sigma-Aldrich (St. Louis, MO, USA). Methanol for high performance liquid chromatography (HPLC) was acquired from Dinamica (Rio de Janeiro, Rio de Janeiro, Brazil). The hard gelatin capsules were purchased from Genix (São Paulo, São Paulo, Brazil). Celulomax ${ }^{\circledR}$ (Lot 0220816) and microcrystalline cellulose (Lot 145000841) were purchased from Embrafarma (São Paulo, São Paulo, Brazil); colloidal silicon dioxide (Lot B5D23LINB6) was purchased from Purifarma (Anapólis, Goiás, Brazil); starch (Lot ALL057603) and talc (Lot ALL50556) were purchased from All Chemis (São Paulo, São Paulo, Brazil). Magnesium carbonate (Lot 16E03-B046-005423) and magnesium stearate (Lot 16G20-B001-008983) were purchased from Fagron (São Paulo, São Paulo, Brazil).

\section{HPLC analysis}

The HPLC analysis was performed using a validated stability-indicating assay method previously developed and validated in our laboratory. Samples were analyzed by a series LC-10A HPLC from Shimadzu (Kyoto, Japan), 
consisting of a LC-20AD pump, a CTO 20-A column oven, a DGU-20A degasser, a SPD-MD20A photodiode array (PDA) detector, a SIL-20-AC HT auto-sampler, and a CBM-20A controller. The chromatographic assay was performed at $25^{\circ} \mathrm{C}$ using a Promosil (Bonna-Agela Technologies, Tianjin, China) reversed-phase $\mathrm{C} 18$ column $150 \times 4.6 \mathrm{~mm}$ (i.d.) with particles of $5 \mu \mathrm{m}$. The mobile phase was a mixture of methanol and water with $\mathrm{pH}$ adjusted to 3.0 using phosphoric acid $(65: 35, \mathrm{v} / \mathrm{v})$. The

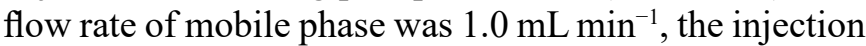
volume was $20 \mu \mathrm{L}$, and UV detection was performed at $241 \mathrm{~nm}$. The UV spectrum in the range of 200-400 $\mathrm{nm}$ was evaluated to determine the similarity index of ROSC peaks in the selectivity studies. The samples were filtered using a $0.45 \mu \mathrm{m}$ syringe filter of hydrophilic polytetrafluoroethylene (PTFE) (Millipore, Bedford, Massachusetts, USA). The retention time of ROSC was approximately $4.5 \mathrm{~min}$. The run time was 10 minutes.

\section{Preparation of crystalline form M of ROSC}

To prepare the crystalline form M of ROSC, the commercial raw material $(1.5 \mathrm{~g})$ was dissolved in $30 \mathrm{~mL}$ of a solution composed by acetonitrile and water (1:1, $\mathrm{v} / \mathrm{v}$ ). The preparation was based on the method previously proposed by Sahadeva and co-workers (Sahadeva et al., 2011). The solution was previously heated to $50 \pm 1{ }^{\circ} \mathrm{C}$ until complete dissolution of ROSC, and after, the solution was cooled at $15 \pm 1{ }^{\circ} \mathrm{C}$. Following, the solution was stirred $(150 \mathrm{rpm})$ at room temperature $\left(25 \pm 1{ }^{\circ} \mathrm{C}\right)$ in an open erlenmeyer flask. After this time, it was observed a considerable amount of particles dispersed in the solvent. The content of the flask was filtered through a 0.45 $\mu \mathrm{m}$ PTFE membrane, and the crystalline powder was recovered on the membrane surface. The powder was left to dry in an oven at $50{ }^{\circ} \mathrm{C}$ for 12 hours, and it was further characterized using different techniques.

\section{Characterization of the solid-state forms}

The assay of ROSC in the raw material before and after recrystallization in our laboratory was performed by the HPLC assay method using the chromatographic conditions previously described $(n=3)$. For this, solutions of the drug at $20 \mu \mathrm{g} \mathrm{mL}^{-1}$ concentration were diluted using a mixture of methanol and water $(65: 35, \mathrm{v} / \mathrm{v})$ before injection into the chromatographic system $(20 \mu \mathrm{L})$.

The diffraction pattern of ROSC was analyzed by $\mathrm{X}$-ray powder diffractometry (XRPD) using an equipment model Rigaku Ultima IV (type II) (Tokyo, Japan). The PXRD measurements were carried out at room temperature under the following conditions: graphite monochromatic $\mathrm{Cu}-\mathrm{K} \alpha$ radiation $\left(\gamma=1.542^{\circ} \mathrm{A}\right)$, voltage of $40 \mathrm{kV}$, current of $30 \mathrm{~mA}$, and a scan rate of $1^{\circ} / \mathrm{min}$ between $3^{\circ}$ and $30^{\circ}$ of the $2 \theta$ range.

Infrared spectra were measured with a Shimadzu IR Affinity-1 Fourier transform infrared (FTIR) spectrophotometer (Shimadzu, Tokyo, Japan) equipped with Attenuated Total Reflection (ATR) sampling accessories Pike Miracle ${ }^{\circledR}$ with zinc selenide $(\mathrm{ZnSe})$ crystals Pike Technologies ${ }^{\circledR}$ (Madison, Wisconsin, USA). The FTIR spectra were recorded at room temperature in the 4,000-600 $\mathrm{cm}^{-1}$ range. After recording a background spectrum, the samples were placed on the ZnSe crystal.

Thermal analysis was carried out using differential scanning calorimetry (DSC) and thermogravimetric analysis (TG). The DSC analysis was performed using a Netzsch-Gerätebau GmbH instrument model DSC 3500 Sirius (Selb, Germany). DSC curves were obtained at a heating rate of $10{ }^{\circ} \mathrm{C} \mathrm{min}{ }^{-1}$ from $30{ }^{\circ} \mathrm{C}$ to $300{ }^{\circ} \mathrm{C}$ under a $\mathrm{N}_{2}$ purge of $50 \mathrm{~mL} \mathrm{~min}^{-1}(\mathrm{n}=3)$. TG was performed using an Exstar TG/DTA-7300 thermogravimetric analyser (Chiba, Japan). TG curves were obtained at a heating rate of $10{ }^{\circ} \mathrm{C} \mathrm{min}^{-1}$ from $30{ }^{\circ} \mathrm{C}$ to $300{ }^{\circ} \mathrm{C}$ under a $\mathrm{N}_{2}$ purge of $50 \mathrm{~mL} \mathrm{~min}^{-1}$.

The equilibrium solubility of ROSC (amorphous solid-state and crystalline form M) was evaluated by the shake-flask method in different aqueous media. The following aqueous media were evaluated: $0.1 \mathrm{~mol} \mathrm{~L}^{-1}$ $\mathrm{HCl}(\mathrm{pH} 1.2)$, pure water, sodium acetate buffer $(\mathrm{pH}$ $4.5)$, sodium acetate buffer ( $\mathrm{pH} 4.5)+$ SDS $0.1 \%(\mathrm{w} / \mathrm{v})$, and potassium phosphate buffer ( $\mathrm{pH}$ 6.8). To determine the equilibrium solubility, an excess of the drug was added to $1 \mathrm{~mL}$ of the aqueous medium, and the solutions were stirred at $150 \mathrm{rpm}$ for $24 \mathrm{~h}$ at $37 \pm 1{ }^{\circ} \mathrm{C}(\mathrm{n}=3)$. The saturated solutions at equilibrium were filtered using a $0.45 \mu \mathrm{m}$ syringe filter of PTFE. Thus, the solutions were successively diluted in mobile phase ( $\mathrm{pH} 3.0)$, and analyzed by the HPLC method.

\section{Formulations}

The mixture of powders (ROSC and excipients) were encapsulated in hard size four gelatin capsules $(\mathrm{n}=120$ ). The formulations containing $20.84 \mathrm{mg}$ of ROSC (corresponding to $20 \mathrm{mg}$ of free base) are described in Table I. All formulations were manufactured with ROSC at amorphous solid-state, with the exception of formulation $\mathrm{D}$ that was prepared with the crystalline form $\mathrm{M}$. The raw materials (amorphous solid-state and crystalline form $\mathrm{M}$ ) were previously ground and sieved in order to standardize their particle size $(75-106 \mu \mathrm{m})$. The set of formulation 
TABLE I - Composition of the ROSC formulations

\begin{tabular}{|c|c|c|c|c|c|c|c|c|}
\hline \multirow{2}{*}{ Components } & \multicolumn{8}{|c|}{$(\%)$} \\
\hline & $\mathbf{A}$ & $\mathbf{B}$ & $\mathbf{C}$ & $\mathbf{D}^{\mathbf{b}}$ & $\mathbf{E}$ & $\mathbf{F}$ & $\mathbf{G}$ & $\mathbf{H}$ \\
\hline Colloidal silicon dioxide & 1.0 & 2.5 & - & 2.5 & 2.5 & 2.5 & 2.5 & 2.5 \\
\hline Talc & 5.0 & 7.5 & - & 7.5 & 7.5 & 7.5 & 7.5 & 7.5 \\
\hline Starch & 74.0 & 81.5 & - & 80.0 & 80.0 & 90.0 & 87.5 & 85.0 \\
\hline Magnesium stearate & - & 1.0 & - & - & - & - & 2.5 & 5.0 \\
\hline Magnesium carbonate & 10.0 & 7.5 & - & 10.0 & 10.0 & - & - & - \\
\hline Microcrystalline cellulose & 10.0 & - & - & - & - & - & - & - \\
\hline Celulomax $E^{\circledR, a}$ & - & - & 100.0 & - & - & - & - & - \\
\hline
\end{tabular}

${ }^{a}$ Commercial powder mixture composed by microcrystalline cellulose, colloidal silicon dioxide, stearic acid, and croscarmellose sodium (superdisintegrant); ${ }^{b}$ Manufactured with the crystalline form M of ROSC.

was selected based on the effect of the excipients on the dissolution properties of the active pharmaceutical ingredient, mainly the negative effect of magnesium stearate, and the positive effect of Celulomax E®, which contains croscarmellose sodium.

These formulations showed satisfactory results for uniformity content and assay of ROSC, with the results within in the range of $95 \%-105 \%$.

\section{DISSOLUTION ASSAYS}

The dissolution profile of ROSC from capsules was performed at $37.0 \pm 0.5^{\circ} \mathrm{C}$ using different experimental conditions. The assays were performed in an Electrolab TDT-08L multi bath $(\mathrm{n}=8)$ dissolution test system (Mumbai, Maharashtra, India) equipped with USP I apparatus (basket) and USP II apparatus (paddle) in accordance with USP General Chapters (USP, 2015).

The dissolution media $(500 \mathrm{~mL})$ evaluated were sodium acetate buffer ( $\mathrm{pH} 4.5)$, sodium acetate buffer $(\mathrm{pH}$ $4.5)+0.1 \%(\mathrm{w} / \mathrm{v}) \mathrm{SDS}$, and potassium phosphate buffer $(\mathrm{pH}$ 6.8). The experimental apparatus tested were basket (USP I apparatus) and paddle (USP II apparatus) using stainless steel sinkers (CAPWST-18, 18.0 x 6.0 mm, SMI-Labhut Ltd., UK) to avoid the floating of the capsules. The stirring speeds of 50 and $100 \mathrm{rpm}$ were studied. The samples $(5 \mathrm{~mL})$ were withdrawn at several times, and they were immediately replaced with equal volume of the dissolution medium. The samples were filtered using quantitative paper filters (Quanty, Germany) and diluted (1:1, v/v) with mobile phase (pH 3.0). Drug quantification was performed by the HPLC method. The dissolution profiles of the ROSC capsules were compared by calculating the dissolution efficacy (DE\%), which was calculated as the percentage of the area under the release curve.

\section{Validation studies}

The dissolution assay method for evaluation of ROSC in gelatin capsules was validated in accordance with the recommendations of the ICH Q2B guidance (ICH, 1995). For this, standard stock standard solutions of ROSC at $1,000 \mu \mathrm{g} \mathrm{mL}^{-1}$ were diluted in pure methanol. The intermediate solutions at $100 \mu \mathrm{g} \mathrm{mL}^{-1}$ were diluted in potassium phosphate buffer $(\mathrm{pH}$ 6.8) (dissolution medium). The working solutions were prepared diluting the intermediate solution with the dissolution medium. The dissolution assay was validated in the following experimental conditions: $500 \mathrm{~mL}$ of phosphate buffer $(\mathrm{pH}$ 6.8 ) at $37.0 \pm 0.5^{\circ} \mathrm{C}$ using USP I apparatus at $100 \mathrm{rpm}$. The formulation $\mathrm{E}$ was selected for validation studies.

The selectivity of the dissolution assay method was determined by evaluating the solutions of the placebo, standard solutions of ROSC at concentration of $20 \mu \mathrm{g}$ $\mathrm{mL}^{-1}$, and sample solutions of the powder mixture of the capsules diluted at this same concentration. The peak purity of the samples was analyzed using a PDA detector for determining the similarity index. Linearity $(n=3)$ was determined by analysis of ROSC standard solutions at five concentration levels $\left(5,10,15,20\right.$, and $\left.25 \mathrm{mg} \mathrm{L}^{-1}\right)$. The dilutions were prepared on three different days (n $=3$ ). The correlation coefficient ( $\mathrm{r}$ ) and the calibration equation $(\mathrm{y}=a \mathrm{x}+b)$ were calculated, where $a$ corresponds to the slope and $b$ is the linear coefficient (intercept). The limit of detection (LOD) and limit of quantitation (LOQ) were calculated from the calibration equation using the following equations:

$L O D=\frac{S D \times 3}{a}$

(Equation 1) 


$$
L O Q=\frac{S D \times 10}{a}
$$

(Equation 2)

where SD is the standard deviation of the intercept, and $a$ is the slope of the calibration equation.

The intraday and interday precision $(n=6)$ of the dissolution assay method were determined by the amount of drug dissolved at 30 minutes (Q30 min), and expressed as relative standard deviation (RSD) according to equation 3:

$$
R S D=\frac{\text { Standard deviation }}{\text { Average value }}
$$

(Equation 3)

The accuracy was evaluated by adding known amounts of ROSC standard substance to the placebo mixture of formulation $\mathrm{E}$ once the formulation exhibited enhanced dissolution properties. A standard stock solution containing $5 \mathrm{mg} \mathrm{mL}^{-1}$ of ROSC standard substance was prepared in the mobile phase, and aliquots of 3, 4, and $5 \mathrm{~mL}$ of standard stock solution were added to vessels with dissolution medium for a total volume of $500 \mathrm{~mL}$, achieving the final concentrations of $30.0,40.0$, and 50.0 $\mu \mathrm{gL}^{-1}(\mathrm{n}=3)$. The solutions were diluted $(1: 1, \mathrm{v} / \mathrm{v})$ in the same way that samples of the dissolution test using the mobile phase ( $\mathrm{pH} 3.0)$. These concentrations correspond to $75 \%, 100 \%$, and $125 \%$ of the final concentration. Aliquots were withdrawn at 30 minutes, and samples were analyzed by the HPLC method. The recovery percentage (RE, \%) was calculated according to Equation 4.

$$
R E=\frac{\text { Experimental concentration }}{\text { Theoretical concentration }}
$$

(Equation 4)

\section{RESULTS AND DISCUSSION}

The amorphous state does not have a threedimensional long-range order as crystalline materials. While the crystalline state is thermodynamically favored for solids, which is characterized by its three-dimensional order of the molecules within the crystal lattice, the amorphous state has been characterized by the random conformation of the molecules. As a result, amorphous state is thermodynamically unstable and may convert to a stable crystalline state. However, this entropic process of conversion may be slow, and more stable amorphous forms are sometimes isolated and used to produce pharmaceutical dosage forms. In this case, the active pharmaceutical ingredient at amorphous state may have higher solubility than corresponding crystals, also showing increased dissolution rates and better compression characteristics. However, it may be less stable chemically and physically than their crystalline forms (Cruz-Cabeza, Reutzel-Edensb, Bernsteincd, 2015).

The commercial raw material of ROSC was characterized as an amorphous powder using thermal analysis (Figure 2A) and XRPD (Figure 3). The amorphous solid was characterized by the absent of peaks in the $\mathrm{X}$-ray diffractogram (Figure 3), and at same time by the absence of a well-defined thermal event corresponding to the melting point in the DSC curve (Figure 2A). For the amorphous powder, the DSC curve exhibited an endothermic thermal event from $50{ }^{\circ} \mathrm{C}$ up to $100{ }^{\circ} \mathrm{C}$, representing the water losses from the raw material. The mass losses were determined by TG $(3.7 \%$ at 100 $\left.{ }^{\circ} \mathrm{C}\right)$. The second endothermic event is not a well-defined peak in the DSC curve, and it was associated with the melting of the amorphous solid, which was confirmed by visual analysis using capillary tubes and a melting point apparatus, indicating a range of values around 152-161 ${ }^{\circ} \mathrm{C}$. The third and final thermal event in the DSC curve of the amorphous powder corresponds to thermal degradation of ROSC, occurring at an increased rate from $158^{\circ} \mathrm{C}$. Thermal degradation of ROSC was confirmed by mass losses using TG.

The crystalline form $\mathrm{M}$ was prepared in our laboratory, and characterized by the XRPD, indicating peaks at 3.29, 5.28, 6.80, 7.50, 9.30, 10.34, 11.72, 13.14, $17.64,18.67,20.41,22.17$, and 22.48 of the $2 \theta$ range (Figure 3). These peaks has the same position to those observed in form $\mathrm{M}$, which was first characterized by Sahadeva and co-workers (Sahadeva et al., 2011), allowing the identification of this crystalline structure. The DSC curve of this crystalline structure (Figure 2B) exhibited an initial endothermic peak at $68{ }^{\circ} \mathrm{C}$, corresponding to solvent losses, which was confirmed by TG $(2.6 \%)$. The second endothermic thermal event from DSC curve appears around $103{ }^{\circ} \mathrm{C}$, corresponding to a temperaturemediated solid-state transformation. The melting point of crystalline form $\mathrm{M}$ was a well-defined endothermic peak at $176{ }^{\circ} \mathrm{C}$, and it was confirmed by visual analysis using capillary tubes and a melting point apparatus ( $>$ $168^{\circ} \mathrm{C}$ ). Following, thermal degradation of ROSC from the crystalline structure started at $190{ }^{\circ} \mathrm{C}$, being clearly observed by TG. To confirm the temperature-mediated solid-state transformation, the crystalline form $\mathrm{M}$ was heated up to $105^{\circ} \mathrm{C}$ for $2 \mathrm{~h}$, and DSC and XRPD analysis were performed. These results were not previously reported, and the peaks from the crystalline form $\mathrm{M}$ after heating were observed at $3.38,5.40,6.80,10.46,13.19$, $17.55,19.03,21.44$, and 22.69 of the $2 \theta$ range (Figure 3 ). 

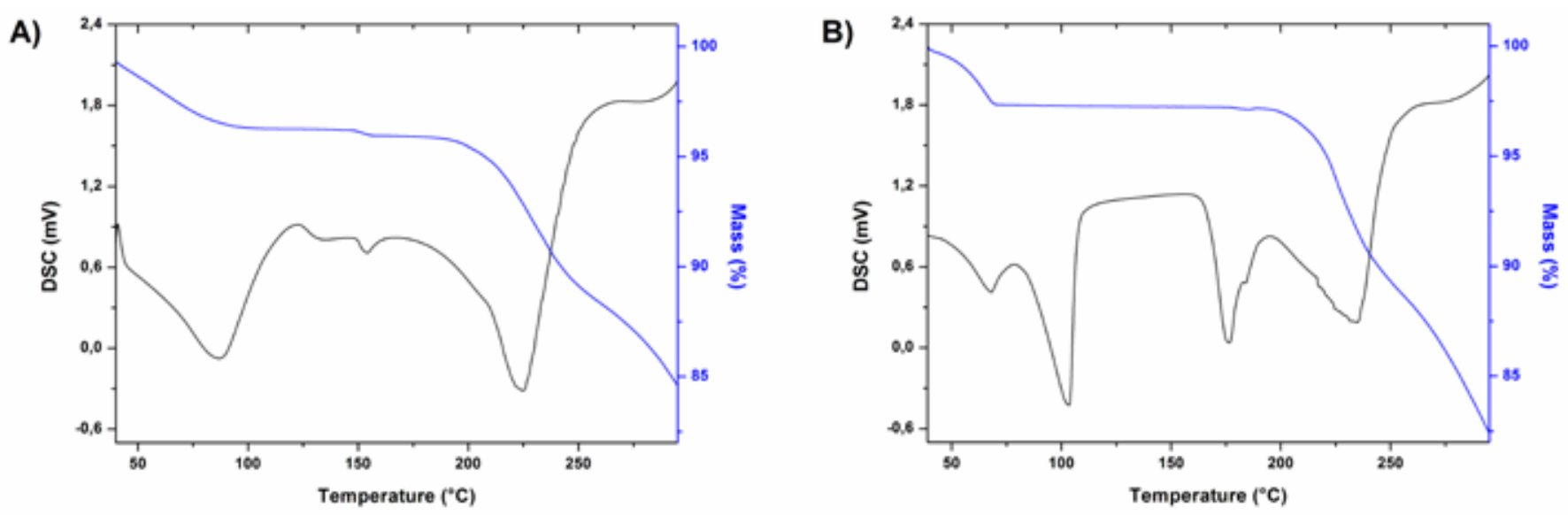

FIGURE 2 - DSC and TG curves of ROSC: A) Amorphous powder; B) Crystalline form M.

The DSC of crystalline form $\mathrm{M}$ after heating did not indicate a endothermic thermal event around $100{ }^{\circ} \mathrm{C}$, which was previously observed in figure $2 \mathrm{~B}$; however, a well-defined endothermic peak was observed at $175^{\circ} \mathrm{C}$, which was related to its melting point (Data not shown).

The ATR-FTIR spectra (Figure 4) of the ROSC (crystalline form $\mathrm{M}$ and amorphous solid-state) allowed the identification of the functional moieties in its chemical structure. The infrared stretching frequencies observed were aromatic $\mathrm{v}=1,540.7 \mathrm{~cm}^{-1}(\mathrm{C}=\mathrm{C}), \mathrm{v}=1,436.9 \mathrm{~cm}^{-1}$ $(\mathrm{C}-\mathrm{H}), \mathrm{v}=1,379.1 \mathrm{~cm}^{-1}(\mathrm{O}=\mathrm{S}=\mathrm{O}), \mathrm{v}=1,151.5 \mathrm{~cm}^{-1}(\mathrm{C}-\mathrm{O})$, and aromatic $\mathrm{v}=775.9 \mathrm{~cm}^{-1}(\mathrm{C}-\mathrm{H})$.

The assay of ROSC in raw material was performed by HPLC method, and indicated a value of $99.83 \% \pm$ $0.44 \%$ for amorphous solid and $99.94 \% \pm 0.37 \%$ for the crystalline form $\mathrm{M}$.

The HPLC method for analysis of ROSC in dissolution medium (using phosphate buffer $\mathrm{pH} 6.8$ as diluent) was validated using a mixture of mobile phase (pH 3.0) as a sample diluent. The calibration equation and correlation coefficient $(\mathrm{r})$ were $\mathrm{y}=49,091( \pm 465) \mathrm{x}$ $+25,595( \pm 1,247)$ and 0.999688 , respectively. The drug response was linear over the concentration range of 1 to $25 \mu \mathrm{g} \mathrm{mL}^{-1}$. The LOQ and LOD were calculated, and the values found were $0.35 \mu \mathrm{g} \mathrm{mL}^{-1}$ and $0.12 \mu \mathrm{g} \mathrm{mL}^{-1}$, respectively. Results for accuracy and precision of analytical method were considered satisfactory, and they were shown in Table II. The criteria adopted for precision and recovery were the same employed for the assay of raw material and for capsule dosage form.

The equilibrium solubility of ROSC showed a $\mathrm{pH}$ dependent behavior related to the ionization of the carboxylic acid moiety $(\mathrm{pKa}=4.6)$ at higher $\mathrm{pH}$ values (Figure 5). The solubility of amorphous solid was larger than the crystalline structure in the media evaluated, which is relative to enhanced thermodynamic properties (e.g., solubility) of amorphous state due to its higher internal energy. The solubility of ROSC in media with acid $\mathrm{pH}$ values showed minor differences between amorphous solid and the crystalline structure. The amorphous powder showed a solubility of $0.53 \pm$ $0.01 \mathrm{mg} \mathrm{mL}^{-1}$ in $0.1 \mathrm{~mol} \mathrm{~L}^{-1} \mathrm{HCl}$ against $0.42 \pm 0.06 \mathrm{mg}$ $\mathrm{mL}^{-1}$ for crystalline form $\mathrm{M}$. The solubility of ROSC in medium sodium acetate buffer ( $\mathrm{pH} 4.5$ ) was determined with and without the addition of anionic surfactant SDS at $0.1 \% \mathrm{w} / \mathrm{v}$. The results obtained in the medium sodium acetate buffer ( $\mathrm{pH} 4.5$ ) without SDS were $2.42 \pm 0.09$ $\mathrm{mg} \mathrm{mL}^{-1}$ for amorphous solid, and $2.00 \pm 0.01 \mathrm{mg} \mathrm{mL}^{-1}$ for crystalline form $\mathrm{M}$. When the SDS was added to medium sodium acetate buffer ( $\mathrm{pH} 4.5)$, the solubility values were $2.21 \pm 0.04 \mathrm{mg} \mathrm{mL}^{-1}$ for amorphous powder, and $2.14 \pm 0.03 \mathrm{mg} \mathrm{mL}^{-1}$ for crystalline form M. From these results, it was demonstrated that solubility of ROSC did not improve by the addition of surfactant in the medium, indicating that micellar solubilization of the hydrophilic drug was not an efficient strategy to increase its solubility. The differences in the equilibrium solubility of the amorphous solid was better evidenced in phosphate buffer $\mathrm{pH} 6.8\left(14.34 \pm 1.86 \mathrm{mg} \mathrm{mL}^{-1}\right.$ for amorphous solid, and $5.73 \pm 0.66 \mathrm{mg} \mathrm{mL}^{-1}$ for the crystalline form M) and water (7.64 $\pm 0.24 \mathrm{mg} \mathrm{mL}^{-1}$ for amorphous solid, and $4.13 \pm 0.58 \mathrm{mg} \mathrm{mL}^{-1}$ for the crystalline form M). After the solubility measurements, the solid precipitate were characterized using XRPD, and the results indicated a solution-mediated phase transformation from the crystalline form $\mathrm{M}$ of the ROSC to the amorphous solid. The major peaks of the crystalline structure were still observed in the X-ray diffractogram of the precipitate after $24 \mathrm{~h}$, but with a very low intensity (Data not shown). These results are counterintuitive, once that solids at amorphous state has higher free energy than their corresponding crystals. In 

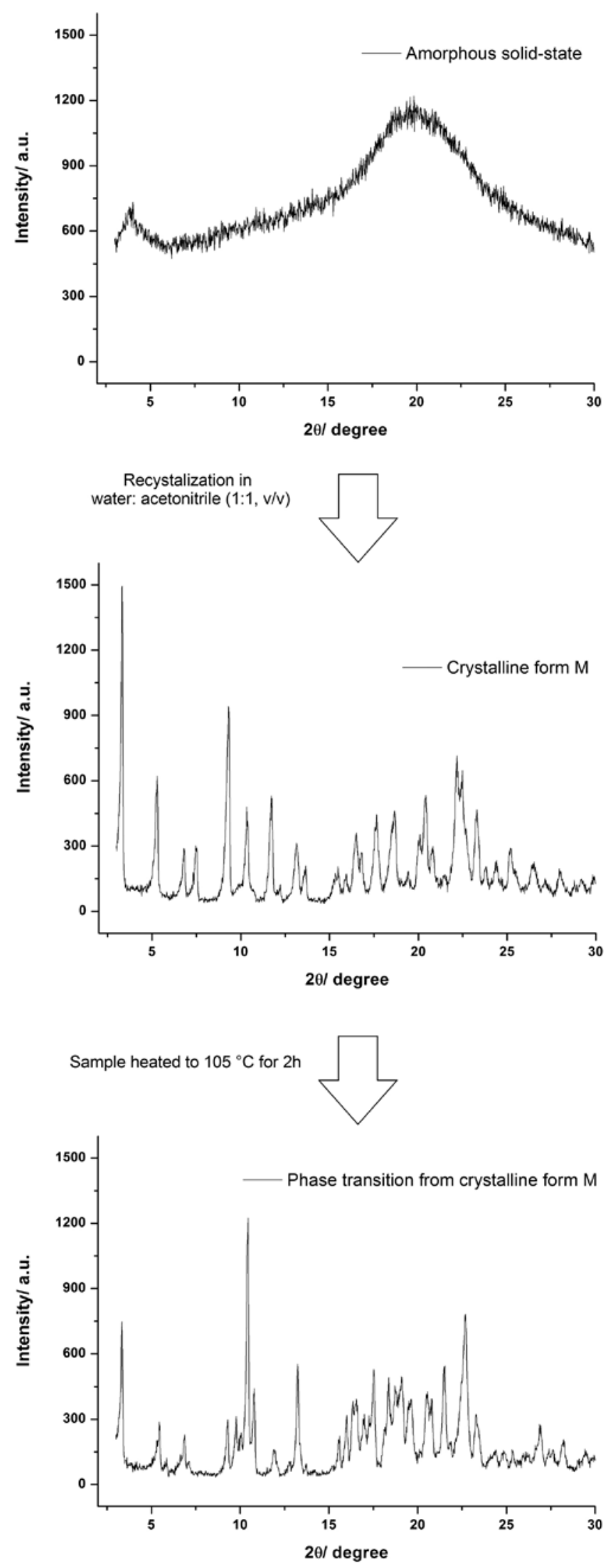

FIGURE 3 - XRDP of ROSC: amorphous solid-state; crystalline form $\mathrm{M}$, and its phase transition after heating to $105^{\circ} \mathrm{C}$ for $2 \mathrm{~h}$.
TABLE II - Precision and accuracy of the dissolution method for ROSC capsules

\begin{tabular}{cccc}
\hline \multicolumn{3}{c}{ Precision $\left(\mathbf{Q}_{30 \min }\right)^{\mathbf{a}}$} & Accuracy \\
\hline $\begin{array}{c}\text { Intraday } \\
(\mathbf{n}=\mathbf{6})\end{array}$ & $\begin{array}{c}\text { Interday } \\
(\mathbf{n}=\mathbf{1 2})\end{array}$ & $\mathbf{\%}$ & $\begin{array}{c}\text { Recovery } \pm \\
\mathbf{S D}^{\mathbf{b}}(\mathbf{n}=\mathbf{3})\end{array}$ \\
\hline & & 75 & $98.76 \pm 0.37$ \\
$97.94 \pm 1.62$ & $98.99 \pm 1.41$ & 100 & $100.7 \pm 0.11$ \\
& & 125 & $99.95 \pm 0.86$ \\
\hline
\end{tabular}

${ }^{\mathrm{a}} \mathrm{Q}_{30 \min }$, amount of drug released at 30 minutes (formulation E); ${ }^{\mathrm{b}} \mathrm{SD}$, Standard deviation.

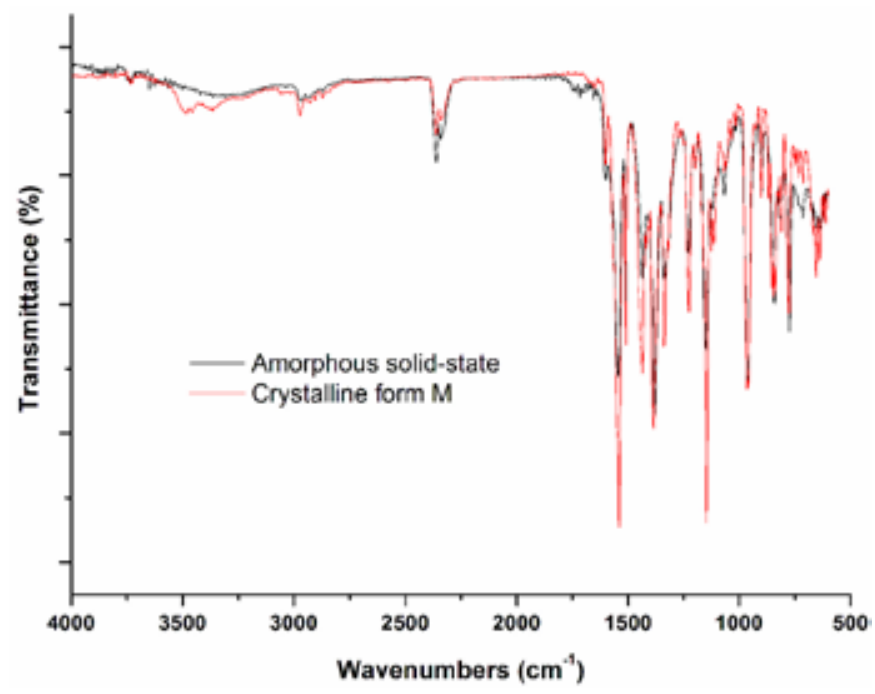

FIGURE 4 - IR spectra of ROSC in amorphous solid-state and crystalline form $M$.

this way, the hypothetical explanation for this solutionmediated transformation may associate with crystal $\mathrm{M}$, once this crystalline structure is not spontaneously obtained at room temperature, being necessary to heat the ROSC solution in acetonitrile and water, $1: 1 \mathrm{v} / \mathrm{v}$ until $50{ }^{\circ} \mathrm{C}$, and after cooling the drug solution at $15^{\circ} \mathrm{C}$ to induce its precipitation. During the equilibrium solubility measurements, the assays were carried out at $37^{\circ} \mathrm{C}$, and at these conditions, the soluble drug precipitated as an amorphous powder instead of this crystalline structure, which must be associated with a more stable amorphous state of ROSC. The evidence that crystalline form $\mathrm{M}$ has a temperature-mediated solid-state transformation when it is heated until $105^{\circ} \mathrm{C}$ may also support these results, demonstrating that some crystalline structures of this drug are only obtained under heating. Considering the $\mathrm{pH}$ dependent behavior of ROSC, which is related to its ionization at higher values of $\mathrm{pH}$, the large solubility of amorphous powder at $\mathrm{pH} 6.8$ may be associated with combined factors acting together as drug ionization and 


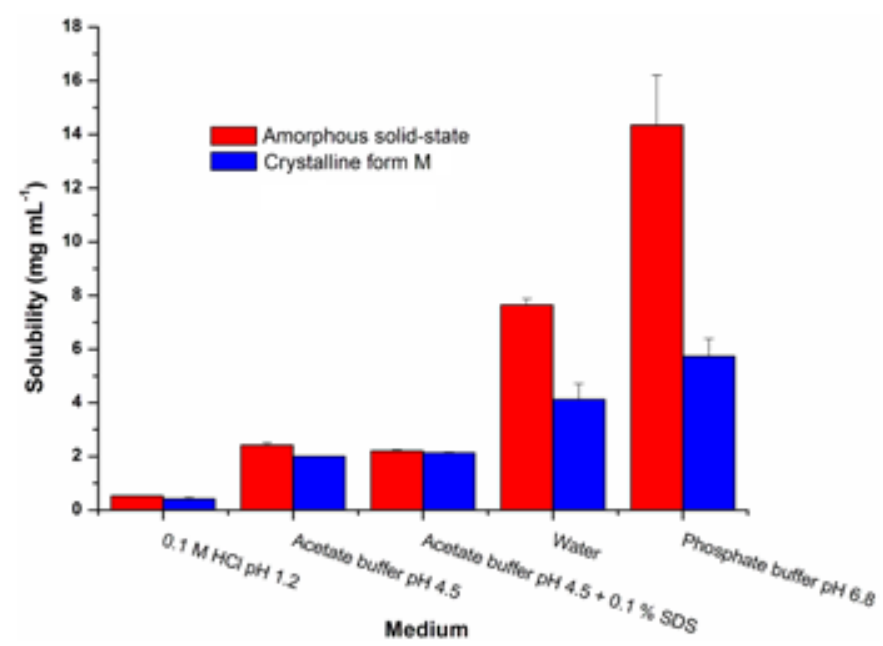

FIGURE 5 - Solubility of ROSC in aqueous media at $37^{\circ} \mathrm{C}(\mathrm{n}=3)$.

the solution-mediated transformation of form $\mathrm{M}$ into amorphous powder, resulting in an enhanced solubility of $\mathrm{ROSC}$ at higher $\mathrm{pH}$ values.

The solubility studies demonstrated that sink conditions were achieved in each medium evaluated for both crystalline form $\mathrm{M}$ and amorphous solid. The criteria adopted for sink conditions was to obtain a saturated solution of drug in the aqueous media with a concentration at least three times higher than the drug concentration determined at the end of dissolution testing. When the method assures sink conditions, the drug solubility in the dissolution medium is not a limiting factor for its dissolution rate. Due to the occurrence of sink conditions in vivo, the biological relevance of these dissolution media is improved (Cardot, Beyssac, Alric, 2007; Bonfilio et al., 2012). Thus, ROSC was soluble in the evaluated aqueous media, assuring sink conditions in a broad $\mathrm{pH}$ range (1.2 to 6.8). According to Biopharmaceutical Classification System, this drug is highly soluble; its major tablet dosage

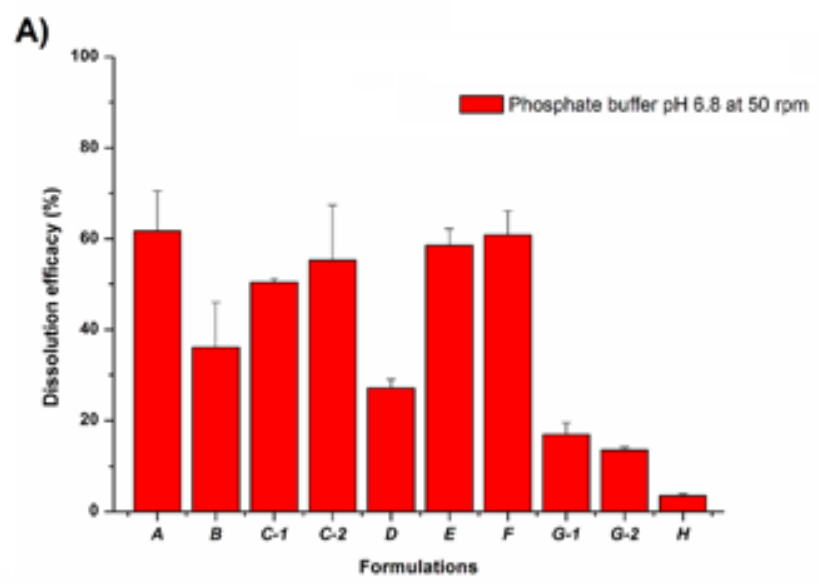

FIGURE 6 - Dissolution efficacy (\%) of ROSC capsules $(n=6)$. is $40 \mathrm{mg}$, and this amount of drug can be easily dissolved in $250 \mathrm{~mL}$ of the aqueous media in the $\mathrm{pH}$ range from 1.2 to 6.8 (solubility $>0.16 \mathrm{mg} \mathrm{mL}^{-1}$ ). Considering that ROSC formulations are usually manufactured using the amorphous powder, this salt must be classified as a class III drug, which was already previously reported (Peng et al., 2009).

The formulations described in Table I were evaluated under several experimental conditions in order to select a dissolution test for evaluating ROSC capsules with increased discriminatory power. Based on this, the ROSC formulations must provide an immediate-release profile, improving the drug availability for absorption on GI tract. The DE\% was selected as a satisfactory parameter to compare the dissolution properties from the formulation set (Figure 6). The formulations were firstly evaluated at $50 \mathrm{rpm}$ in the medium potassium phosphate buffer $\mathrm{pH}$ 6.8 due to the increased drug solubility at this $\mathrm{pH}$ value (Figure 6A). All formulations were evaluated using USP I apparatus (basket); this experimental apparatus is usually employed for evaluating capsules, avoiding its fluctuation. However, formulations codified as C-2 and G-2 were also evaluated using USP apparatus II (paddle). The results indicated that the experimental apparatus at $50 \mathrm{rpm}$ showed a minor effect on the dissolution properties of ROSC capsules in the medium potassium phosphate buffer $\mathrm{pH} 6.8$ ( $p>0.05$, Student t-test). The formulation $C$ containing a superdisintegrant agent (sodium croscarmellose) showed high values of $\mathrm{DE} \%(>50 \%)$ according to expected, while the formulation $\mathrm{G}$ containing $2.5 \%$ of magnesium stearate showed low values of DE\% $(<20 \%)$. The negative effect of magnesium stearate in the $\mathrm{DE} \%$ is well known. This hydrophobic pharmaceutical adjutant can decrease the wettability of the formulations with the dissolution medium and, consequently, their dissolution rates. The

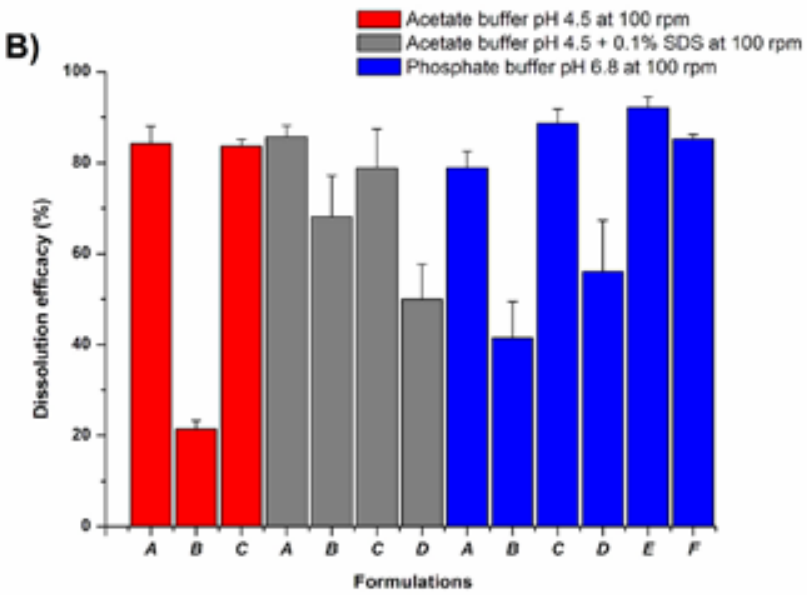


$\mathrm{DE} \%$ values were decreased when magnesium stearate concentration was increased as observed from the results obtained with formulations B $(36.1 \% \pm 9.9 \%), G(17.7 \%$ $\pm 2.6 \%)$, and $\mathrm{H}(3.5 \% \pm 0.4 \%)$, containing respectively, $1 \%, 2.5 \%$, and $5 \%$ of magnesium stearate.

The formulation D and E contain the same composition of excipients; however, they were manufactured with different solid forms of ROSC. The formulation $\mathrm{D}$ was prepared using crystalline form $\mathrm{M}$, and its $\mathrm{DE} \%$ value was $27.1 \% \pm 1.9 \%$, while the amorphous solid (formulation E) exhibited a DE\% value of $58.6 \% \pm$ $3.6 \%$. These results were associated with the increased solubility coefficients of the amorphous powder, increasing the dissolution rate of ROSC from formulation E.

The ROSC capsules were evaluated at different media at $100 \mathrm{rpm}$ (acetate buffer $\mathrm{pH} 4.5$ with or without SDS, and phosphate buffer $\mathrm{pH}$ 6.8) using USP apparatus I (Figure 6B). The results obtained using USP apparatus II for formulation $\mathrm{A}, \mathrm{B}$, and $\mathrm{C}$ in three different media (acetate buffer $\mathrm{pH} 4.5$ without SDS, acetate buffer $\mathrm{pH} 4.5$ with SDS, and phosphate buffer pH 6.8) were similar to those using USP apparatus I, indicating a minor effect of the experimental apparatus at $100 \mathrm{rpm}$ on the dissolution properties of ROSC capsules (Data not shown; $p>0.05$, Tukey post-hoc test). The results indicated that aqueous media had a major effect on dissolution properties from formulation B (contains 1\% of magnesium stearate) in comparison with formulations $\mathrm{A}$ and $\mathrm{C}$. The formulation A showed enhanced dissolution properties as compared to $\mathrm{C}, \mathrm{E}$, and $\mathrm{F}$. The formulation $\mathrm{B}$ showed a minor $\mathrm{DE} \%$ in the medium acetate buffer $\mathrm{pH} 4.5$ without SDS (21.4\% $\pm 1.9 \%$ ), and a major $\mathrm{DE} \%$ in the medium acetate buffer pH 4.5 with SDS $(68.1 \% \pm 9.0 \%)$. Besides the ROSC has a similar solubility in acetate buffer $\mathrm{pH} 4.5$ with or without SDS, the results demonstrated that the presence of SDS increased the DE\% of formulation B; the surfactant

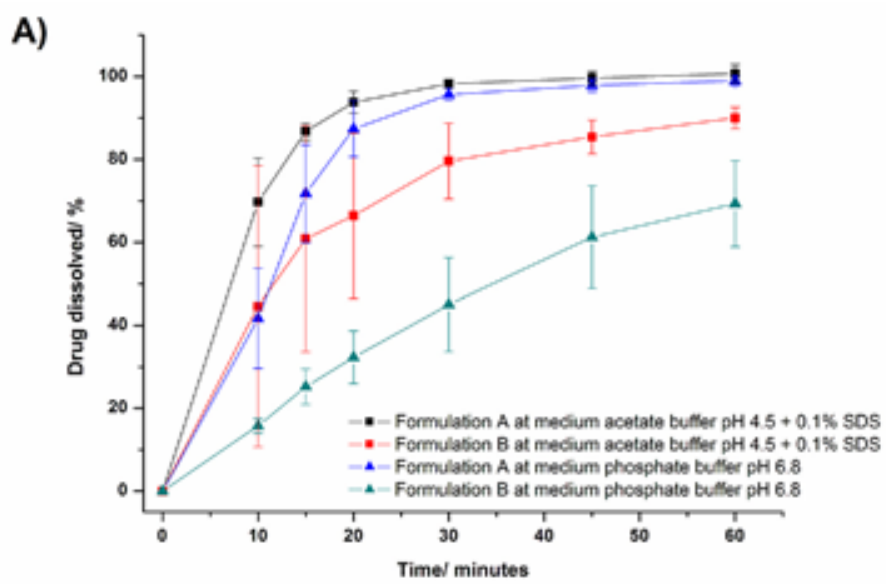

increased the wettability of this formulation. From these results, the medium acetate buffer $\mathrm{pH} 4.5$ with SDS was not considered a promising dissolution medium for ROSC capsules, showing low discriminatory power (Figure 7A). $\mathrm{DE} \%$ of formulation $\mathrm{B}$ in medium phosphate buffer $\mathrm{pH}$ 6.8 was $41.5 \pm 8.0 \%$, and this increased value of $\mathrm{DE} \%$ of formulation $\mathrm{B}$ in medium phosphate buffer $\mathrm{pH} 6.8$ was $41.5 \% \pm 8.0 \%$, and this increased value of $\mathrm{DE} \%$ was related to the major drug solubility in this experimental condition. The medium phosphate buffer $\mathrm{pH} 6.8$ also showed a considerable discriminatory power between the formulations with or without magnesium stearate. The capsule formulation prepared with the crystalline form $\mathrm{M}$ (formulation $\mathrm{D}$ ) was also evaluated in medium acetate buffer $\mathrm{pH} 4.5$ with SDS and phosphate buffer $\mathrm{pH} 6.8$ at 100 $\mathrm{rpm}$, showing DE\% values of $49.9 \% \pm 7.8 \%$ and $56.1 \%$ $\pm 11.2 \%$, respectively. According to these results, the formulation D exhibited very similar dissolution profiles (Figure 7B) in both media, being able to discriminate between the different solid-state forms of the ROSC. In this way, the medium phosphate buffer $\mathrm{pH} 6.8$ was selected considering the major drug solubility, and its discriminating power for evaluating ROSC capsules was satisfactory using USP apparatus I at $100 \mathrm{rpm}$.

\section{CONCLUSIONS}

Based on our results, we suggest that dissolution properties of hydrophilic drugs with high solubility in water may be overrated in dissolution media including surfactant. This phenomenon occurs due to the improved wettability of the formulations in the presence of surfactant, leading to an increased dissolution rate of the hydrophilic drugs and loss of discriminatory power among the formulations. On the other hand, dissolution media with surfactants were able to discriminate between

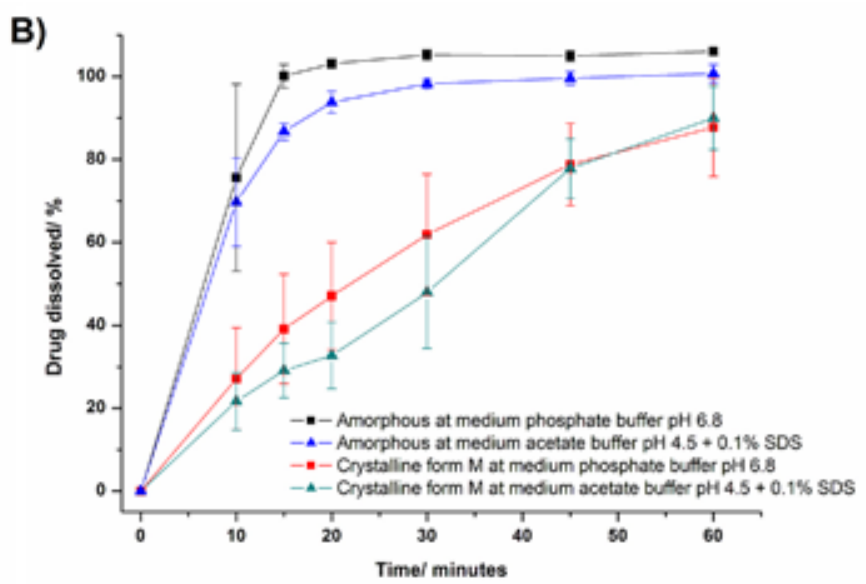

FIGURE 7 - Dissolution profiles of ROSC capsules from different media using basket at $100 \mathrm{rpm}(\mathrm{n}=6)$. 
the amorphous powder and crystalline form M of ROSC, once that the surfactant SDS did not increase its solubility. In this way, the selected conditions to perform dissolution testing of ROSC capsules were $500 \mathrm{~mL}$ of potassium phosphate buffer ( $\mathrm{pH}$ 6.8) using basket apparatus at 100 $\mathrm{rpm}$. The specification of $85 \%$ of drug dissolved at 30 minutes was recommended as single-point specification for the routine analysis of quality control of ROSC capsules.

\section{ACKNOWLEDGEMENTS}

The authors are grateful for Programa Nacional de Pós-Doutorado/ Coordenação de Aperfeiçoamento de Pessoal de Nível Superior (PNPD/CAPES), Conselho Nacional de Desenvolvimento Científico e Tecnológico (CNPq), Fundação de Amparo à Pesquisa do Estado de Minas Gerais (FAPEMIG: grant FAPEMIGAPQ-01819-14) for research fellowships.

\section{COMPLIANCE WITH ETHICAL STANDARDS}

\section{CONFLICT OF INTEREST} interest.

The authors declare that they have no conflict of

\section{REFERENCES}

Alshora DH, Haq N, Alanazi FK, Ibrahim MA, Shakeel FJ. Solubility of rosuvastatin calcium in different neat solvents at different temperatures. Chem Thermodyn. 2016;94:230-233.

Balakumar K, Raghavan CV, Selvan N T, Prasad R H, Abdu S. Self nanoemulsifying drug delivery system (SNEDDS) of Rosuvastatin calcium: Design, formulation, bioavailability and pharmacokinetic evaluation. Colloids Surfaces B Biointerfaces. 2013;112:337-343.

Blatter F, Van Der Schaaf A, Szelagiewicz M. Crystalline forms of rosuvastatin calcium salt. Patent No. US20080194604A1. Blatter F, Van Der Schaaf A, Szelagiewicz M; 2006. Blatter Van Der Schaaf, Szelagiewicz; 2006.

Bonfilio R, Pires SA, Ferreira LMB, de Almeida AE, Doriguetto AC, de Araújo MB, et al. A discriminating dissolution method for glimepiride polymorphs. J Pharm Sci. 2012;101(2):794-804.
Bonfilio R, Leal JS, Santos OMM, Pereira GR, Doriguetto AC, de Araújo MB. Analysis of chlorthalidone polymorphs in raw materials and tablets and the effect of forms I and II on the dissolution properties of drug products. J Pharm Biomed Anal. 2014;88:562-570.

Booth RJ, Cittern PA, Crabb JN, Horbury J, Jones DWC. Crystalline form of bis [(E)-7-[4-(4-fluoro-phenyl)-6-isopropyl2-[methyl(methyl-sulfonyl)amino]pyrimidin-5-yl](3R,5S)3,5-dihydroxyhept-6-enoic acid] Calcium Salt. Patent No. US20100222373A1. AstraZeneca UK Limited; 2009.

Cardot JM, Beyssac E, Alric M. In vitro - In vivo correlation: importance of dissolution in IVIVC. Dissolut Technol. 2007; 1519. DOI: dx.doi.org/10.14227/DT140107P15

Corrêa JCR, Perissinato AG, Serra CHR, Trevisan M G, Salgado HR N. Polymorphic stability of darunavir and its formulation. J Therm Anal Calorim. 2016;123(3):2185-2190.

Cruz-Cabeza AJ, Reutzel-Edensb SM, Bernsteincd J. Facts and fictions about polymorphism. Chem Soc Rev. 2015;44:86198635 .

Hoti E, Censi R, Ricciutelli M, Malaj L, Barboni L, Martelli S, et al. Validation of an HPLC-MS method for rociverine tablet dissolution analysis. J Pharm Biomed Anal. 2008;47(2):422428.

International Conference on Harmonisation. ICH. Validation of Analytical Procedures: Methodology, Q2B (CPMP/ ICH/281/95); 1995.

Lee D, Roh H, Son H, Jang SB, Lee S, Nam SY, et al. Pharmacokinetic interaction between rosuvastatin and metformin in healthy Korean male volunteers: A randomized, open-label, 3-period, crossover, multiple-dose study. Clin Ther. 2014;36(8):1171-1181.

Li J, Volpe D A, Wang Y, Zhang W, Bode C, Owen A, et al. Use of transporter knockdown caco-2 cells to investigate the in vitro efflux of statin drugs. Drug Metab Dispos. 2011;39(7):11961202.

Matsui K, Tsume Y, Amidon GE, Amidon GL. The evaluation of in vitro drug dissolution of commercially available oral dosage forms for itraconazole in gastrointestinal simulator with biorelevant media. J Pharm Sci. 2016;105(9):2804-2814. 
Moffat AC, Osselton MD, Widdop B. Clarke's analysis of drug and poisons: in pharmaceuticals, body fluids and postmortem material. 4 ed. London: Pharmaceutical Press; 2011. 2609 p.

Nishiguch S, Inakoshi N. Novel crystalline form of rosuvastatin calcium and production method therefor. Patent No. WO2014050874A1. Towa Pharmaceutical Co., Ltd.; 2013.

Patil-Gadhe A, Pokharkar V. Pulmonary targeting potential of rosuvastatin loaded nanostructured lipid carrier: Optimization by factorial design. Int J Pharm. 2016;501(1-2):199-210.

Peng SX, Rockafellow BA, Skedzielewski TM, Huebert ND, Hageman W. Improved pharmacokinetic and bioavailability support of drug discovery using serial blood sampling in mice. J Pharm Sci. 2009;98(5):1877-1884.

Peppas NA, Narasimhan B. Mathematical models in drug delivery: How modeling has shaped the way we design new drug delivery systems. J Control Release. 2014;190:75-81.

Qureshi SA. Developing discriminatory drug dissolution tests and profiles: Some thoughts for consideration on the concept and its interpretation. Dissolut Technol. 2006;18-23.

Sahadeva RM, Satyanarayana RM, Srinivasa RN, Thirumalai RS. Novel polymorph of bis[(e)-7-[4-(4-fluorophenyl)-6iso-propyl-2-[methyl(methylsulfonyl)amino]pyrimidin-5-yl] (3r,5s)-3,5-dihydroxyhept-6-enoic acid] calcium salt. Patent No. WO2012011129A2. Msn Laboratories Limited; 2011.

Sethi MK, Rawat V, Yerramalla R, Bontalakoti JMR, Vemula L, Ayyaran K, et al. Novel polymorphic forms of rosuvastatin calcium and process for preparation of the same. Patent No. WO2011074016A1. Matrix Laboratories Ltd; 2010.
Shen H, Su H, Liu T, Yao M, Mintier G, Li L, et al. Evaluation of rosuvastatin as an organic anion transporting polypeptide (OATP) probe substrate: in vitro transport and in vivo disposition in cynomolgus monkeys. J Pharmacol Exp Ther. 2015;353(2):380-391.

Snider DA, Addicks W, Owens W. Polymorphism in generic drug product development. Adv Drug Deliv Rev. 2004;56(3):391395.

Šterk D, Zaugg W, Beutler U, Loeser EM, Prasad K, Časar Z. Efficient and highly stereoselective assembly of rosuvastatin. Tetrahedron Lett. 2016;57(12):138-1341.

Taylor NP. Crystalline bis[(e)-7-[4-(4-fluorophenyl)-6isopropyl-2-[methyl (methylsulfonyl) amino]pyrimidin-5-yl] (3r,5s)-3,5-dihydroxyhept-6-enoic acid]calcium salt. Patent No. WO2000042024A1. Astrazeneca Ab; 1999.

United States Pharmacopeia. USP. 38 ed. National Formulary 33. Rockville: United States Pharmacopeial Convention; 2015.

Varma MV, Rotter CJ, Chupka J, Whalen KM, Duignan DB, Feng B, Litchfield J, Goosen TC, El-Kattan AF. pH-Sensitive Interaction of HMG-CoA reductase inhibitors (Statins) with organic anion transporting polypeptide 2B1. Mol Pharm. 2011;8(4):1303-1313.

Zhou C, Gao W, Lu G, Ding J, Wu X, Huang X, et al. Preparation, characterization and in vitro release of microparticles based on dextran-rosuvastatin conjugate. Carbohydr Polym. 2013;96(1):156-161.

Received for publication on $24^{\text {th }}$ August 2017 Accepted for publication on $12^{\text {th }}$ June 2018 